\title{
Determinants of Farmers' Health Behaviors on Poisoning with Pesticides in Golestan Province: Based on the Health Belief Model
}

\author{
Ali Zafarzadeh ${ }^{1}$, Seyd Kamal Mirkarimi ${ }^{2 *}$, Abotaleb Bay ${ }^{3}$, Ahmad Heidari ${ }^{4}$ \\ 1. Environmental Health Research Center, Golestan University of Medical Sciences, Gorgan, Iran. \\ 2. Environmental Health Research Center, Golestan University of Medical Sciences, Gorgan, Iran. \\ 3. Health Management and Social Development Research Center, Golestan University of Medical Sciences, Gorgan, \\ 4. Department of Research and Technology, Golestan University of Medical Sciences, Gorgan, Iran.
} Iran.

*Correspondence: Environmental Health Research Center, Golestan University of Medical Sciences, Gorgan, Iran. Tel: +98.9112731646. Email:ak.mirkarimi@gmail.com

Received Sep 01, 2018; Accepted July 20, 2019

\section{Abstract}

Background: Pesticides are chemical compounds which are used to fight against and to control plant and animal pests as vectors of diseases. In view of being exposed to pesticides, farmers are at high risk of occupational diseases. In this regard, the predictability of Health Belief Model (HBM) has been confirmed for the studies in promoting health behaviors. The aim of the study was to investigate the determinants of health behaviors of farmers on poisoning with pesticides in Golestan province based on HBM.

Methods: This cross-sectional study was conducted on 394 pregnant women referred to Gorgan health centers in 2017. Samples were selected by multi-stage stratified sampling method from Gorgan health centers in Golestan province. Data was gathered using self-report questionnaire. Data analysis was performed using chi-square test, Fisher's exact, and Kruskal-Wallis tests in SPSS-16. The P-value less than 0.05 were considered significant.

Results: $32.7 \%$ of women were received complete preconception care and $17.8 \%$ had no prepregnancy care. Only $44.2 \%$ of women used folic acid daily since the first trimester of pregnancy. Most of pregnant women (63.7\%) performed triple screening laboratory test (FBS, CBC, TSH). Preconception care was more successful in mothers with higher level of education $(\mathrm{P}<0.001)$, having health insurance $(\mathrm{P}<0.001)$, history of disease $(\mathrm{P}=0.027)$, higher family income $(\mathrm{P}=0.044)$, and nulliparity $(\mathrm{P}=0.049)$.

Conclusions: Preconception care coverage and acid folic consumption is not optimal. It seems necessary to plan more precisely on how such services need to be provided. The identification of 
factors associated with this care showed that far less attention was paid among low-income, without assurance coverage and low-educated people. Since these people do not have enough money to take care of mother and infant during pregnancy, health policymakers should provide the related services for free.

Keywords: Preconception Care, Pregnant Woman, Reproductive Health

$\underline{10.29252 / j g b f n m \cdot 16.2 .41}$

\section{Introduction}

The world's increasing need for food has led producers towards more production. In this regard, pesticides have been widely used for controlling pests, however due to the high risks of pesticides in agriculture along with its advantages, the tendency to use alternative methods has grown in the world over the past years $(1,2)$. Dealing with these toxic chemicals such as preparing and spraying, as well as keeping and storing may create great hazards for farmers, farm owners, and pesticide holders. However, the vast exposure to industrial risks in many careers needs safety measures to be applied, but a great number of workers ignore safety principles (3).

Damages from pests can lead to significant reduction in yield and income. Therefore, pesticides are yearly consumed to avoid these problems, (4). Recent studies have indicated that the residual pesticides in human organs cause serious consequences such as poisoning, abortion, skin and neurological complications, behavioral disorders, and cancer (5). The use of pesticides is more than normal in many developing countries; and consequently their unscientific and unregulated use gives rise to serious damage to ecosystems and human health (6).

The number of poisonings with pesticides is more than 500,000 cases per year with 20,000 deaths. It is noteworthy that the rate of poisoning in developing countries is 13 times higher than fully industrialized countries accounting for $85 \%$ of the global pesticide production (7).

Farmers are mostly faced with the high risk of occupational diseases which is caused through exposure to pesticides and while there is inadequate training and safety. Furthermore, the observance of health and safety measures during using pesticides and the application of safety equipment as well as paying attention to recommendations and guidelines of agricultural experts are greatly effective in preventing risks of pesticides (8).

In this regard, the theory-based studies are more beneficial than other interventions in influencing health-related behaviors (9) since the studies determine intervention development methods and provide a guide to evaluate interventions (10). In order to improve farmers' performance during the process of using pesticides, reasons and factors affecting their behavior should be investigated. The Health Belief Model is a psychological and educational model in the health education which emphasizes that the individual perception may cause motivations leading to create optimal behaviors. The structures of this model includes the perceived susceptibility and severity, perceived barriers and benefits, and self-efficacy and guidance for action (11). The Health Belief Model mainly focuses on perceived benefits of individual health and perceived threats or risks of a particular outcome against perceived benefits of performing a specific activity or behavior change (12). The effectiveness of the Health Belief Model has been investigated and approved in a research by Bay and Heshmati on factors associated with 
pesticides (3). Furthermore, the significant impact of the structures of this model has been portrayed in other similar studies such as the empowerment of livestock breeders against high risk behavior of Malta fever (13), reducing mobile phone use in driving (14), and promoting oral hygiene behavior (15), all of which are about promotional behavior. According to the abovementioned issues, the present study has investigated the determinants of farmers' health behaviors during pesticide poisoning in East Golestan province based on the Health Belief Model.

\section{Methods}

This cross-sectional study was done on male farmers of Azadshahr County, Golestan province in 2015. The research was approved by Golestan University of Medical Sciences (Project code: 94040974).

The inclusion criteria were being an active farmer in the field of agriculture and horticulture and willing to participate in the study. Questionnaires, which were incomplete, were excluded from the research.

Samples were selected through multistage cluster sampling from health care centers in Azadshahr. At first, 7 rural healthcare centers with a greater amount of using pesticides were randomly selected from Azadshahr County. Two health houses, from two villages, were chosen from each health center. From each village, 21 families with having at least a farmer in family were randomly assigned to complete the questionnaire. Sample size was 294 based on a study by Raksanam et al. on the health behavior of Thailand's paddy field farmer in facing with pesticides (16).

After obtaining informed consent from participants, the questionnaires were completed through the self-administered method. A briefing was held for precise collection of information and completion of questionnaires.

The data was gathered using a 3-part questionnaire including demographic information, behavior and constructs of the Health Belief Model. Demographic characteristics included information about age, educational attainment, and type and amount of pesticide. The Behavior part, included 18 Yes/No questions; score 1 was assigned to the Yes, and Score 0 to the No. The reverse scoring was performed in questions in which No was the correct answer. Therefore, the scores ranged from 0 to 18. The Health Belief Model questionnaire consist of six subscales as follows. Perceived susceptibility (seven 4-likert items that the scores ranged from 0 to 21) Perceived intensity (six 4-likert items that scores ranged from 0 to 18) Perceived benefits (six 4-likert items that scores ranged from 0 to 18) Perceived barriers (ten 4-likert items that scores ranged from 0 to 30). Perceived self-efficacy (eight 5-likert items that scores ranged from 0 to 32), Cues to action including 11 two-choice questions that score 1 was assigned to Yes and score 0 to No answers that scores ranged from 0 to 11 . The Validity and reliability of behavior questionnaire and constructs of the Health Belief Model were studied and approved by Bay et al. (17). To determine the reliability of questionnaire, a pilot study with a sample size of 25 participants was done and the reliability of each subscales of questionnaire was confirmed by an alpha coefficient ranging from 0.71 to 0.79 . In order to make it possible to compare scores of all model constructs, the final score was from 100 to make the comparison possible because of different numbers of questions and scores.

Data were analyzed using SPSS version 18.0 (IBM, USA). Data are presented as mean values \pm SD and frequency. Pearson correlation coefficient, Spearman correlation coefficient, one-way 
ANOVA, and linear regression were used to examine research hypotheses. Normal data distribution was examined using Shapiro-Wilk test. The significance level was less than 0.05.

\section{Results}

The mean age of samples was $46.12 \pm 11.45$ years (range from 17 to 75 ). The mean work experience of participants was $23.4 \pm 12.54$ years (range from 1 to 60 ). (Table 1 )

Table 1.Demographic characteristics of studied farmers $(n=294)$

\begin{tabular}{|l|l|c|c|}
\hline Variables & Groups & $\mathbf{N}$ & $\mathbf{\%}$ \\
\hline \multirow{4}{*}{ Race } & Fars & 106 & 36.1 \\
\cline { 2 - 4 } & Turkmen & 94 & 32 \\
\cline { 2 - 4 } & Sistani and Baluch & 34 & 11.5 \\
\cline { 2 - 4 } & Turkic & 60 & 20.4 \\
\hline \multirow{4}{*}{ Education } & Illiterate & 48 & 16.3 \\
\cline { 2 - 4 } & Under high school diploma & 177 & 60.1 \\
\cline { 2 - 4 } & High school diploma & 48 & 16.3 \\
\cline { 2 - 4 } & Higher than high school diploma & 21 & 7.1 \\
\hline \multirow{5}{*}{ Product type } & Garden & 13 & 4.4 \\
\cline { 2 - 4 } & Agricultural & 248 & 84.4 \\
\cline { 2 - 4 } & Vegetables & 3 & 1 \\
\cline { 2 - 4 } & Garden - agricultural & 26 & 8.8 \\
\cline { 2 - 4 } & Agricultural - Vegetables & 4 & 1.3 \\
\hline \multicolumn{2}{|l|}{ Age } & Mean & SD \\
\hline Work experience & 46.12 & 11.45 \\
\hline
\end{tabular}

Television programs (226(76.9\%)), and pesticide sellers (201(68.4\%)) accounted for the most frequent cues to action in the use of pesticides, while the radio programs $(64(21.8 \%))$ and the newspapers (74(25.2\%)) displayed the least frequent cues to action. (Table 2)

Table 2. Frequency of "cue to action" construct in the use of agricultural pesticides $(n=294)$

\begin{tabular}{|l|c|c|c|c|}
\hline \multirow{2}{*}{ Cues to action } & \multicolumn{2}{|c|}{ Yes } & \multicolumn{2}{c|}{ No } \\
\cline { 2 - 5 } & N & $\%$ & N & $\%$ \\
\hline Newspaper & 74 & 25.2 & 220 & 74.8 \\
\hline Radio & 64 & 21.8 & 230 & 78.2 \\
\hline Television & 226 & 76.9 & 68 & 23.1 \\
\hline Healthcare provider & 166 & 56.5 & 128 & 43.5 \\
\hline Poster and Pamphlet & 81 & 27.6 & 213 & 72.4 \\
\hline
\end{tabular}




\begin{tabular}{|l|c|c|c|c|}
\hline Health Expert & 79 & 26.9 & 215 & 73.1 \\
\hline Agriculture Jihad staff & 122 & 41.5 & 172 & 58.5 \\
\hline Agriculture office & 116 & 39.5 & 178 & 60.5 \\
\hline Other Farmers & 174 & 59.2 & 120 & 40.8 \\
\hline Pesticide sellers & 201 & 68.4 & 93 & 31.6 \\
\hline Children & 120 & 40.8 & 173 & 58.8 \\
\hline
\end{tabular}

The mean aligned scores from 100 relating to determinants of the study such as perceived susceptibility, perceived intensity, perceived benefits, perceived barriers, self-efficacy and cues to action were equal to $58.48,55.08,80.25,44.11,18.24$ and 79.44 respectively.

The Findings indicated that $89 \%$ of research participants wore long pants, $94.2 \%$ wore longsleeved shirts, $67 \%$ wore gloves, $76.5 \%$ wore masks, $32.7 \%$ wore glasses with face shield, $33.7 \%$ wore special clothes, and $46.9 \%$ wore non-penetrating shoes. Also, the percentage of manual spraying equipment users was $61.9 \%$.

The most commonly amount of pesticides used were herbicide and fungicide (16.7\%), herbicide $(10.8 \%)$ and diazinon $(10.4 \%)$ respectively. Furthermore, $17.1 \%$ of different insecticides were also utilized. A significant relationship found between the type of consumed pesticides and the amount of the use of pesticides. $(\mathrm{p}=0.05)$

The Pearson correlation coefficient test did not indicate any significant correlation between the work experience and the amount of consumed poison $(\mathrm{p}=0.249)$. Based on obtained results of Spearman correlation coefficient, there was a significant relationship between the amount of consumed pesticides and the educational attainment of the farmers $(\mathrm{p}=0.024)$. According to Table 3, there was a positive and significant correlation between cue to action with perceived barriers and self-efficacy $(\mathrm{p}=0.001)$. However, there was no statistical significant relationship between the amount of consumed pesticide and other determinants of study.

The linear regression was used to investigate the predictive power of Health Belief Model constructs on farmers' behavior (amount of consumed pesticide). All variables entered the model using forward method. In the adjusted model, only perceived barrier construct predicted farmers' behavior $(\beta=0.208, \mathrm{p}=0.004)$ (Table 4). 
Table 3. Correlation between Health Behavior and Health Belief Model constructs in Farmers

\begin{tabular}{|c|c|c|c|c|c|c|c|c|}
\hline & & $\begin{array}{l}\text { Amount } \\
\text { of pesti- } \\
\text { cide }\end{array}$ & $\begin{array}{l}\text { Perceived } \\
\text { suscepti- } \\
\text { bility }\end{array}$ & $\begin{array}{l}\text { Perceived } \\
\text { severity }\end{array}$ & $\begin{array}{l}\text { Perceived } \\
\text { benefits }\end{array}$ & $\begin{array}{l}\text { Perceived } \\
\text { barriers }\end{array}$ & $\begin{array}{l}\text { Perceived } \\
\text { self- } \\
\text { efficacy }\end{array}$ & $\begin{array}{l}\text { Cues } \\
\text { to ac- } \\
\text { tion } \\
\end{array}$ \\
\hline \multirow{2}{*}{$\begin{array}{l}\text { Amount } \\
\text { of pesti- } \\
\text { cide }\end{array}$} & $\begin{array}{l}\text { Pearson } \\
\text { correlation }\end{array}$ & 1 & -0.045 & 0.040 & -0.038 & 0.121 & 0.053 & 0.087 \\
\hline & $\mathbf{P}$ & & 0.459 & 0.513 & 0.539 & 0.047 & 0.385 & 0.154 \\
\hline \multirow{2}{*}{$\begin{array}{l}\text { Perceived } \\
\text { suscepti- } \\
\text { bility }\end{array}$} & $\begin{array}{l}\text { Pearson } \\
\text { correlation }\end{array}$ & -0.045 & 1 & 0.543 & 0.249 & 0.227 & -0.016 & 0.004 \\
\hline & $\mathbf{P}$ & 0.459 & & 0.001 & 0.001 & 0.001 & 0.785 & 0.939 \\
\hline \multirow{2}{*}{$\begin{array}{l}\text { Perceived } \\
\text { severity }\end{array}$} & $\begin{array}{l}\text { Pearson } \\
\text { correlation }\end{array}$ & 0.040 & 0.543 & 1 & 0.297 & 0.310 & 0.010 & 0.010 \\
\hline & $\mathbf{P}$ & 0.513 & 0.001 & & 0.001 & 0.001 & 0.859 & 0.864 \\
\hline \multirow{2}{*}{$\begin{array}{l}\text { Perceived } \\
\text { benefits }\end{array}$} & $\begin{array}{l}\text { Pearson } \\
\text { correlation }\end{array}$ & -0.038 & 0.249 & 0.297 & 1 & 0.095 & -0.002 & 0.057 \\
\hline & $\mathbf{P}$ & 0.539 & 0.001 & 0.001 & & 0.104 & 0.979 & 0.332 \\
\hline \multirow{2}{*}{$\begin{array}{l}\text { Perceived } \\
\text { barriers }\end{array}$} & $\begin{array}{l}\text { Pearson } \\
\text { correlation }\end{array}$ & 0.121 & 0.227 & 0.310 & 0.095 & 1 & -0.423 & -0.331 \\
\hline & $\mathbf{P}$ & 0.047 & 0.001 & 0.001 & 0.104 & & 0.001 & 0.001 \\
\hline \multirow{2}{*}{$\begin{array}{l}\text { Perceived } \\
\text { self- } \\
\text { efficacy }\end{array}$} & $\begin{array}{l}\begin{array}{l}\text { Pearson } \\
\text { correlation }\end{array} \\
\end{array}$ & 0.053 & -0.016 & 0.010 & -0.002 & -0.423 & 1 & 0.345 \\
\hline & $\mathbf{P}$ & 0.385 & 0.785 & 0.859 & 0.979 & 0.001 & & 0.001 \\
\hline \multirow{2}{*}{$\begin{array}{l}\text { Cues to } \\
\text { action }\end{array}$} & $\begin{array}{l}\begin{array}{l}\text { Pearson } \\
\text { correlation }\end{array} \\
\end{array}$ & 0.087 & 0.004 & 0.010 & 0.057 & -0.331 & 0.345 & 1 \\
\hline & $\mathbf{P}$ & 0.154 & 0.939 & 0.864 & 0.332 & 0.001 & 0.001 & \\
\hline
\end{tabular}

Table 4. Prediction of farmer's hygienic behavior in the use of pesticides based on health belief model (HBM) constructs using the linear regression model

\begin{tabular}{|l|c|c|c|c|}
\hline \multirow{2}{*}{ Theoretical constructs } & \multicolumn{2}{|c|}{ Non-adjusted } & \multicolumn{2}{c|}{ Adjusted } \\
\cline { 2 - 5 } & $\boldsymbol{\beta}$ & Std. Error & $\boldsymbol{\beta}$ & P-value \\
\hline Constant & 0.042 & 1.561 & & 0.979 \\
\hline Perceived susceptibility & -0.013 & 0.010 & -0.092 & 0.188 \\
\hline Perceived severity & 0.005 & 0.010 & 0.034 & 0.640 \\
\hline Perceived benefits & -0.008 & 0.010 & 0.047 & 0.460 \\
\hline Perceived barriers & 0.044 & 0.015 & 0.208 & 0.004 \\
\hline Perceived self-efficacy & 0.014 & 0.011 & 1.97 & 0.089 \\
\hline Cues to action & 0.024 & 0.012 & 0.126 & 0.059 \\
\hline
\end{tabular}




\section{Discussion}

The mean aligned score from 100 for determinants indicated that perceived benefits the highest score was 80.25 , the lowest score of self-efficacy was 18.24 and the cue to action score was 79.44. Despite the fact that people were aware of benefits of behavior, they had low self-efficacy indicating the need for raising the farmers' awareness of the pesticides provision and using.

In the present study, the most commonly-used pesticides were reported herbicides and fungicides. in another study in Khuzestan province, herbicides and insecticides also showed the highest intake among agricultural pesticides; and accordingly the result was consistent with the present study (18).

With regard to obtaining health information, cues to action, by farmers about the use of pesticides, the most widely used source of information belonged first to the TV educational programs and then to the pesticide sellers. The foremost issue is expectable due to the per capita television watching in Iran. The pesticide sellers were the second source of information; hence, providing educational program for this group (as an influential group) seems particularly beneficial to provide health-related information and promote farmers' health behavior for the proper and healthy use of agricultural pesticides. On the other hand, newspapers and radio programs were introduced as sources to be of less interest for farmers in obtaining information about pesticides. This is also justifiable considering the low level of education the majority of participants (76.4\%)., Asghari et al. in their research, illustrated that the most important sources of information were through relevant lessons presented by companies (e.g. pamphlets, booklets and posters), while the was trained by head of department and using media such as radio programs and television- took the second and third priorities (19) which were in line with the finding of present study. In fact, the head of department acted as pesticide sellers and the television programs represented the main source of information essentially the same as that used in the present study.

Results of a research by Gesesew et al. (20) in Ethiopia indicated that most of the samples were cognizant of the ways to deal with poisons such as breathing and digestion; and it was consistent with other studies $(21,22)$,however it was showed that only a few of participants were obviously aware of the risks of skin contact with pesticides (20). In another comparable study by Zyoud et al (23) in Palestine, 85.8\% and 57.7\% of farmers were well acquainted with harmful effects of agricultural pesticides on the health and environment conditions. As entitled by Hashemi et al. (24), farmers' perception of the safe use of insecticides indicated a significant relationship between the educational status and the safe use of insecticides; which was thoroughly consistent with the present study. Hashemi et al. also portrayed a significant relationship between the experience of using pesticides and the safe provision of pesticides, while there was no significant relationship between the work experience and the amount of consumed pesticides in the present study. In a similar way, other recent studies have also demonstrated a significant relationship between higher education level and the safe use of insecticides $(25,26)$.

The determinants of farmers' health behavior were divided into two categories: perceived barriers and self-efficacy. Since the educational degree of most of the participants were high school diploma or less, the self-efficacy and perceived barriers were probably formed due to the lack of enough knowledge about the different types of pesticides, methods and the amount of the use of pesticides. Blackman et al. predicted four factors of farmers' self-efficacy for the safe use of pesticides including age, sex, work experience and previous use of pesticides. Their study also indicated that farmers' acquaintance with the use of pesticides at work showed the greatest

J Res Dev Nurs Midw, Volume 16, Number 2, December, 2019 
impact on the self-efficacy in emergencies (27). This emphasizes the importance of pesticide sellers' up-to-date information as a major cue to action in the present study. In this regard, Kuruppu and Liverman have already noted that the perceived self-efficacy was largely influenced by farmers' past experience with environmental stressors (28).

In an attempt by Jemberu et al., it was entitled that the farmers' intention to take control measures for oral and eating-borne diseases, perceived barriers were the only significant predictor of the intention to get vaccinated (29). It was probably due to the cost of getting vaccinated in their study.

In the present study, there was no significant correlation between perceived susceptibility and severity with the amount of using pesticides. The research performed by Lucas and Allen (12), reported that $65 \%$ of farmers were not well informed on long-term and harmful effects of exposure to pesticides. This was probably ascribed to the fact that the effects of being exposed to pesticides (e.g. skin bruises, respiratory symptoms, nausea, vomiting and headache), were often of acute symptoms, the issue which was predictable through the participants` low educational level.

Finally, perceived barriers were arrayed as the only predictors of health behavior in farmers. Therefore, it seems beneficial to provide allied training and skills about perceived barriers which leads to design effective interventions. Furthermore, owing to the significant and influential role of Agriculture Jihad Organization in providing accurate and applied information for farmers, the results of the present project will be available to the organization in order to provide necessary backgrounds for making more principled decisions and greater participation of organization.

\section{Conclusion}

The majority of participants had low level of education which was high school diploma or less; hence, it seems beneficial to design society-based interventions to raise farmers' awareness and skills to enhance their self-efficacy according to main sources of information such as TV educational programms, pesticide sellers and healthcare providers.

\section{Acknowledgements}

We are deeply grateful to the Deputy of Research and Technology at Golestan University of Medical Sciences regarding financial support for the present project numbered 2950/35/ P.G and. We would also like to show our gratitude to Ms. Nasimeh Yousefian, and the colleagues in the Department of Public Health and Center for Research and Health. 


\section{References}

1. Beseler C, Stallones L, Hoppin JA, Alavanja MC, Blair A, Keefe T, Et al. Depression and pesticide exposures in female spouses of licensed pesticide applicators in the agricultural health study cohort. J Occup Environ Med. 2006; 48(10): 1005-13.

2. Ye M, Beach J, Martin JW, Senthilselvan A. Occupational pesticide exposures and respiratory health. Int J Environ Res Public Health. 2013; 10(12): 6442-71.

3. Abotaleb B, Heshmati H. Factors associated with pesticide use behaviors among farmworkers based on health belief model. Iran J Public Health. 2016; 45(2): 276-7.

4. Hosseini ZJ, Shorafa S, Dashti G, Hayati B, Kazemiyeh F. An economic evaluation of the environmental benefits from pesticides reduction program in khuzestan province. journal of Agricultural science and sustainable production. 2010; 20 (4):101-112.[persian]

5. Hasany AH, Sayadi M, Jafari S. Investigation of pesticides effect on groundwater quality of shemiran villages. Water and Wastewater. 2011; 23(8):119-129.[persian]

6. Devi PI. Health risk perceptions, awareness and handling behaviour of pesticides by farm workers. Agricultural Economics Research Review. 2009; 22(2): 45- 70.

7. Janhong K, Lohachit C, Butraporn P, Pansuwan P. Health promotion program for the safe use of pesticides in Thai farmers. Southeast Asian J Trop Med Public Health. 2005; 36(4): 258-261.

8. Magauzi R, Mabaera B, Rusakaniko S, Chimusoro A, Ndlovu N, Tshimanga M, Et al. Health effects of agrochemicals among farm workers in commercial farms of Kwekwe district, Zimbabwe. Pan Afr Med J. 2011; 9:26.

9. Michie S, Abraham C. Interventions to change health behaviours: evidence-based or evidenceinspired?. Psychology \& Health. 2004; 19(1): 29-49.

10. Improved Clinical Effectiveness through Behavioural Research Group. Designing theoreticallyinformed implementation interventions. Implementation Science. 2006 Dec 1;1(1):4.

11. Kalan-Farmanfarma K, Zareban I, Jalili Z, ShahrakiPour M. Effectiveness of education based on the health belief model on performing preventive measures for breast cancer among female teachers in zahedan. J Educ Community Health. 2014; 1(1): 11-18.[persian]

12. Lucas SF, Allen PJ. Reducing the risk of pesticide exposure among children of agricultural workers: How nurse practitioners can address pesticide safety in the primary care setting. Pediatric nursing. 2009; 35(5): 308-317.

13. Babaei V, Garmaroodi G, Batebi A, Alipour D, Shahbaz M, Babazadeh T. The effectiveness of an educational intervention based on the health belief model in the empowerment of stockbreeders against high-risk behaviors associated with brucellosis. UMSHA. 2014; 1(3): 12-9.[persian]

14. Moeini B, Rezapur-Shahkolai F, Faradmal J, Soheylizad M. Effect of an educational program based on the health belief model to reduce cell phone usage during driving in taxi drivers. J Educ Community Health. 2014; 1(2): 56-66.[persian] 
15. Moeini B, Ghaderi A, Hazavehei S, Allahverdipour H, Moghimbeigi A, Jalilian F. A comparative study of peer education and trainer education on the basis of health belief model (hbm) in improving oral health in sanandaj boys'elementary schools. TOLOO-E-BEHDASHT. 2013; 12(2): 1-13. [persian]

16. Raksanam B, Taneepanichskul S, Siriwong W, Robson M. Factors associated with pesticide risk behaviors among rice farmers in rural community, thailand. Journal of Environmental and Earth Science. 2012; 2(2): 32-9.

17. Bay A, Heshmati H. Factors associated with pesticide use behaviors among farmworkers based on health belief model. Iran J Public Health .2016; 45(2): 276.

18. Salehi S, Rezaee Moghadam k, Ajili A. Agricultural specialists' attitude toward and intention for application of vrt-spraying technologies using structural equation modeling. JWSS - Isfahan University of Technology. 2009; 13(47): 757-71.[persian]

19. Asghari M, Taghdisi MH, Haghighi M, Yekefallah D, Abbassinia M, Ahmadnezhad I, Aghaie H. Evaluation of workers' perception about safety in roller and steel parts production factory based on the health belief model in 2011. Occupational medicine Quarterly Journal. 2013 Sep 15;5(2):20-31.

20. Gesesew HA, Woldemichael K, Massa D, Mwanri L. Farmers knowledge, attitudes, practices and health problems associated with pesticide use in rural irrigation villages, southwest ethiopia. PloS one. 2016; 11(9): e0162527.

21. Lekei EE, Ngowi AV, London L. Farmers' knowledge, practices and injuries associated with pesticide exposure in rural farming villages in Tanzania. BMC public health. 2014; 14(1):389.

22. Damalas CA, Eleftherohorinos IG. Pesticide exposure, safety issues, and risk assessment indicators. Int J Environ Res Public Health. 2011; 8(5): 1402-19.

23. Sa'ed HZ, Sawalha AF, Sweileh WM, Awang R, Al-Khalil SI, Al-Jabi SW, Et al. Knowledge and practices of pesticide use among farm workers in the west bank, palestine: safety implications. Environ Health Prev Med. 2010; 15(4): 252-61.

24. Hashemi SM, Hosseini SM, Hashemi MK. Farmers' perceptions of safe use of pesticides: determinants and training needs. Int Arch Occup Environ Health. 2012; 85(1): 57-66.

25. Sam KG, Andrade HH, Pradhan L, Pradhan A, Sones SJ, Rao PG, Et al. Effectiveness of an educational program to promote pesticide safety among pesticide handlers of South India. Int Arch Occup Environ Health. 2008; 81(6): 787-95.

26. Naidoo S, London L, Rother H-A, Burdorf A, Naidoo R, Kromhout H. Pesticide safety training and practices in women working in small-scale agriculture in South Africa. Occup Environ Med. 2010; 67: 823-8.

27. Blackman IR. Factors influencing australian agricultural workers' self-efficacy using chemicals in the workplace. Workplace health \& safety. 2012; 60(11): 489-96. 
28. Kuruppu N, Liverman D. Mental preparation for climate adaptation: The role of cognition and culture in enhancing adaptive capacity of water management in Kiribati. Global Environmental Change. 2011; 21(2): 657-669.

29. Jemberu WT, Mourits M, Hogeveen H. Farmers' intentions to implement foot and mouth disease control measures in ethiopia. PloS one. 2015; 10(9): e0138363.

\section{Bibliographic information of this paper for citing:}

Zafarzadeh A, Mirkarimi SK, Bay A, ET al. Determinants of Farmers' Health Behaviors on Poisoning with Pesticides in Golestan Province: Based on the Health Belief Model.

J Res Dev Nurs Midw, 2019; 16(2), 41-51.

Copyright (C) 2019, Ali Zafarzadeh, Seyd Kamal Mirkarimi, Abotaleb Bay, Ahmad Heidari. 